\title{
How do climate-linked sex ratios and dispersal limit range boundaries?
}

Maria Boyle ${ }^{1 *}$, Lisa E Schwanz ${ }^{1,2}$, Jim Hone ${ }^{1}$ and Arthur Georges ${ }^{1}$

\begin{abstract}
Background: Geographic ranges of ectotherms such as reptiles may be determined strongly by abiotic factors owing to causal links between ambient temperature, juvenile survival and individual sex (male or female). Unfortunately, we know little of how these factors interact with dispersal among populations across a species range. We used a simulation model to examine the effects of dispersal, temperature-dependent juvenile survival and sex determining mechanism (temperature-dependent sex determination (TSD) and genotypic sex determination (GSD)) and their interactions, on range limits in populations extending across a continuous range of air temperatures. In particular, we examined the relative importance of these parameters for population persistence to recommend targets for future empirical research.
\end{abstract}

Results: Dispersal influenced the range limits of species with TSD to a greater extent than in GSD species. Whereas male dispersal led to expanded species ranges across warm (female-producing) climates, female dispersal led to expanded ranges across cool (male-producing) climates. Two-sex dispersal eliminated the influence of biased sex ratios on ranges.

Conclusion: The results highlight the importance of the demographic parameter of sex ratio in determining population persistence and species range limits.

Keywords: Dispersal, GSD, Population dynamics, Range limits, Reptiles, Sex ratio, TSD

\section{Background}

For many organisms, particularly ectothermic animals, individual traits and demographic parameters are linked to temperature, such that ranges could be largely determined by abiotic factors [1,2]. Abiotic factors are often incorporated into the most simple modelling approaches (for example, climate envelope modelling) used to predict the future distributions of organisms [3]. However, there is increasing evidence [3-8] that fast evolutionary changes, dispersal and population dynamics are among the factors that are equally as important as abiotic factors in determining species ranges [3,9]. For example, it has been demonstrated that population dynamics and dispersal can alter a species responses to shifting climates [3]. In particular there can be a considerable lag between climate becoming suitable in any one place and colonisation by a species through dispersal [3]. Across a

\footnotetext{
* Correspondence: Maria.Boyle@canberra.edu.au

'Institute for Applied Ecology, University of Canberra, Canberra ACT 2601, Australia

Full list of author information is available at the end of the article
}

species' range, dispersal can play a key role by expanding ranges outside of a thermal limit (i.e. creating sinks, [10]), [Harts A, Schwanz L, Kokko H: Demography can favour female-advantageous alleles. P R SOC B. submitted], and preventing local adaptation [2]. These issues have gained new imperative for understanding range change in the context of climatic warming.

Colonisation and extinction rates may change spatially due to environmental gradients in habitat characteristics (for example, temperature, rainfall, or humidity) [11]. The role of temperature in demography and range limits may be especially important for species with temperaturedependent sex determination (TSD; $[12,13])$. In these species, individual sex (male or female) is permanently determined during embryonic development by incubation temperature [14]. The proportion of new hatchlings in a population that are male (the Cohort Sex Ratio, or CSR) often shows wide geographical variation associated with climatic or microclimatic variation and their effects on nest temperatures $[15,16]$. Numerous studies have predicted that climate warming will skew 
the cohort sex ratios of reptiles towards females (or males in the tuatara) with negative consequences for population persistence (e.g. [12,15,17-22]). Yet we know very little about how sex ratios in populations of reptiles with TSD limit range boundaries. There has been at least one attempt to explain the geographical distribution of TSD species based on sex ratios, suggesting that imbalanced sex ratios (and marginal habitats) limit population growth at range boundaries [13]. It was proposed that balanced sex ratios are located at range centres (or favourable habitats), and skewed sex ratios at more marginal habitats [13].

The importance of biased sex ratios in limiting the ranges of species with TSD will depend on a few interacting factors. First, climatically-linked juvenile survival may also play a role in determining range boundaries, as eggs only survive at certain temperatures $[16,23]$ [Boyle M, Hone J, Schwanz L, Georges A: Under what conditions do climate-driven sex ratios enhance versus diminish population persistence? Ecology and Evolution. submitted]. Second, the extent to which female-biased sex ratios limit population persistence will depend on how 'limiting' males are (i.e. the dependence of female fecundity on male abundance, [Boyle M, Hone J, Schwanz L, Georges A: Under what conditions do climate-driven sex ratios enhance versus diminish population persistence? Ecology and Evolution. submitted] [24]. If male density is not strongly limiting to female fecundity because of polygyny, sperm storage and sex-specific breeding intervals [25-27], femalebiased populations will have enhanced population growth and persistence [Boyle M, Hone J, Schwanz L, Georges A: Under what conditions do climate-driven sex ratios enhance versus diminish population persistence? Ecology and Evolution. submitted] [28].

Finally, dispersal among populations may bring the rare sex into biased populations, rescuing them from the risk of demographic collapse and potentially leading to expanded ranges. Dispersal by male hatchlings is thought to have an important role in facilitating population persistence in increasingly feminised populations [29]. However, most studies of the effects of climate warming on sex ratios are of isolated populations, and no consideration has been given to the role of dispersal, or the interaction between climaticallylinked sex ratios and sex-specific dispersal in driving population dynamics. For example, in many TSD species dispersal may be inefficient for range expansion under climate change [16]. This suggests that the sensitivity of range limitation to dispersal distance should be examined.

Dispersal in reptiles is thought to be primarily malebiased, although data are sparse and alternative dispersal tendencies (female-biased dispersal or dispersal by both sexes) have not been well investigated [30,31]. For example, male-biased dispersal has been demonstrated in many species of lizards [32,33], snakes [31,34,35], marine turtles [36-39], and in some freshwater turtles [40-42]. Female dispersal has been demonstrated only in an alpine lizard (Niveoscincus microlepidotus) [30].

There are no documented studies of two-sex dispersal in reptiles. A theoretical analysis of two-sex dispersal tendency found it enhanced population persistence in marginal habitats as gene flow through dispersal occurred in both directions [43]. This analysis included benefits associated with choosing habitats to maximize environmental quality and a reduction in inbreeding. However, because there was no population variation in sex ratio, it did not explore the importance of dispersal in recruiting a rare sex into a population.

In this paper, we explore the role of dispersal in determining the extent of population persistence and range limits in species of reptiles with the common TSD pattern $1 \mathrm{~A}$ (females produced at higher temperatures) and compare it to results for species with genotypic sex determination (GSD). We do this across populations that vary spatially, but not temporally, in air temperature. Importantly, we include in this analysis 1) the potential for male limitation on female fecundity when males are rare, and 2) the additional effect of temperature on juvenile survival.

\section{Methods}

\section{Simulation model}

A matrix (100 rows by 100 columns) of 10,000 populations was distributed across a continuous air temperature gradient, with each column assigned a temperature from $18^{\circ} \mathrm{C}$ to $33^{\circ} \mathrm{C}$. Each population in the matrix was initiated with 100 adult males and 100 adult females (for both TSD and GSD species). We projected these populations in a simulation to determine range limits under different scenarios of dispersal and temperature-dependence of sex ratios. Within each population, simulated population operations approximated logistic growth, including density-dependent juvenile survival [Boyle M, Hone J, Schwanz L, Georges A: Under what conditions do climate-driven sex ratios enhance versus diminish population persistence? Ecology and Evolution. submitted].

In each time step, offspring were first produced. The total number of offspring produced was the product of the number of adult females in the population and perfemale fecundity, which was subject to male limitation (see Male Limitation). The number of offspring in each population that were male was sampled using a random binomial distribution (and, hence sex ratio was stochastically determined), given the total number of offspring and the population-specific sex ratio probability of producing a male, $p$. This sex ratio probability depended on population air temperature for TSD scenarios, but was a constant 0.5 for GSD scenarios (see Cohort sex ratio). The number of offspring that recruited as adults into their natal population or a non-natal population (survived to 
and bred at age 1) depended on temperature-dependent juvenile survival (see Juvenile survival) followed by dispersal (see Dispersal function). The number of adults surviving to the next time step was sampled using a random binomial distribution given the initial number of adults and a constant probability of survival $(s=0.95$ for both males and females; average life expectancy of 20 years). There was no adult dispersal.

The population cycle was iterated 1,000 times. Throughout the simulation, populations were counted as extinct if they had either zero adult males or zero adult females, and were excluded from reproduction in that round. Each simulation was replicated ten times and the averaged numbers of extant populations were plotted in ten temperature intervals, each of $1.5^{\circ} \mathrm{C}$ in width, in the range of temperatures in the population matrix. Simulations were performed with MATLAB R2012b.

\section{Male limitation $(B)$}

In our simulation, per-female fecundity, $B$, was an integer that was sampled using a random binomial distribution based on the probability of fertilisation of a female, $\operatorname{Pr}\{f e r t\}$, with a maximum value of $B_{\max }$ :

$$
B=B_{\max } \mathrm{x} \operatorname{Pr}\{f e r t\}
$$

$\operatorname{Pr}\{$ fert $\}$ was described as a function of adult sex ratio (ASR), or the proportion of adults in the population that are male, [24]:

$$
\operatorname{Pr}\{f e r t\}=\frac{A S R}{A S R+b}
$$

The shape parameter for equation $2, b$, represents the relative strength of male limitation on female fecundity. Persistence of isolated TSD populations in female-producing climates is highly sensitive to this parameter [Boyle $\mathrm{M}$, Hone J, Schwanz L, Georges A: Under what conditions do climate-driven sex ratios enhance versus diminish population persistence? Ecology and Evolution. submitted]. However, there are few empirical data available to estimate a likely value. Given the high degree of polygamy and sperm storage in reptiles [25-27], it is unlikely that males are strongly limiting on female fecundity. For this reason, we chose an intermediate level of male limitation $(b=0.01)$ where males only become strongly limiting to female fecundity when they fall below approximately $10 \%$ of the adult population (Figure 1a).

\section{Cohort sex ratio $(p)$}

We examined range limits under two relationships between cohort sex ratio (CSR) and air temperature. The first cohort sex ratio (CSR) curve was flat, with the offspring sex ratio at 0.5 for all air temperatures, describing the pattern for a GSD species (slope $\beta=0$ and intercept of $\alpha=0.5$ ). CSR curve 2 represents a TSD species based upon the parameters derived for the painted turtle [20] with intercept $\alpha=4.14$ and slope $\beta=-0.147$ (see Figure 2a). The sex ratio produced at the long-term average air temperature for painted turtles is 0.6 (proportion of male offspring, [20]. Because we calculated population size for stable air temperatures, $p$ did not fluctuate across years.

\section{Juvenile survival (a)}

The number of juvenile males and females surviving the embryonic stage was sampled using a random binomial
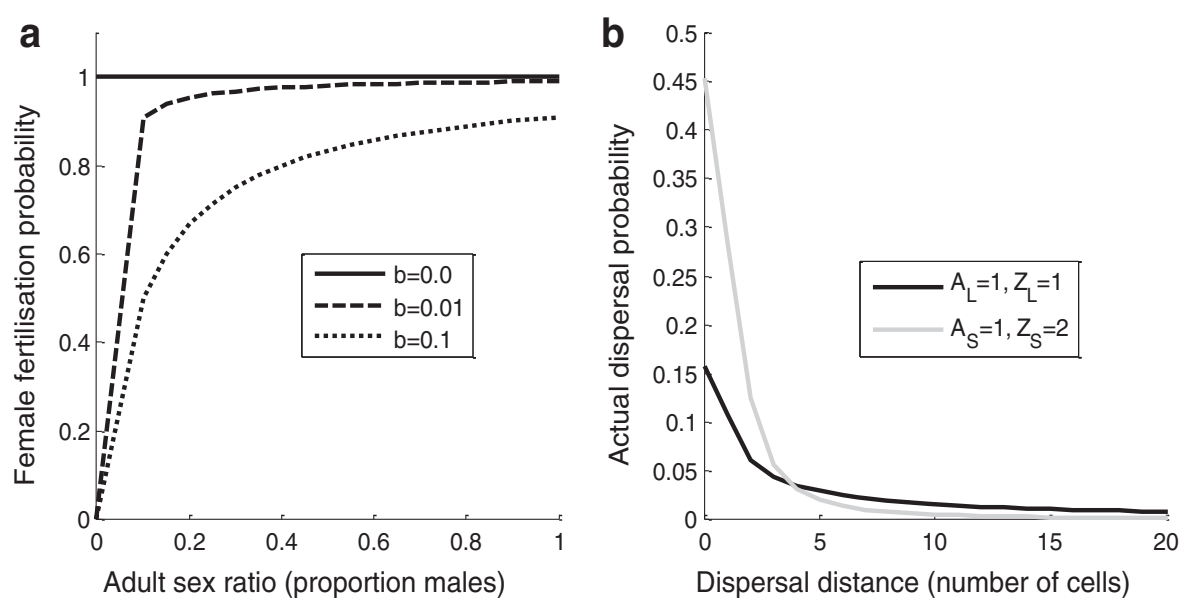

Figure 1 Adult sex ratio and fat-tailed dispersal kernels. (a) The female fertilisation probability as a function of adult sex ratio $(A S R=M /(M+F))$. The different lines represent different sensitivities of fertilisation probability to changes in the ASR (after Rankin and Kokko 2007). (b) Actual probability of an individual moving a certain number of cells (dispersal distance) across a population matrix, according to two fat-tailed dispersal kernels (equation 3). 'Large' dispersal has parameters $A_{L}=1$ and $Z_{L}=1$ (black line) and 'Small' dispersal has parameters $A_{S}=1$ and $Z_{S}=2$ (grey line), where $L=$ Large, and $S=$ Small. 


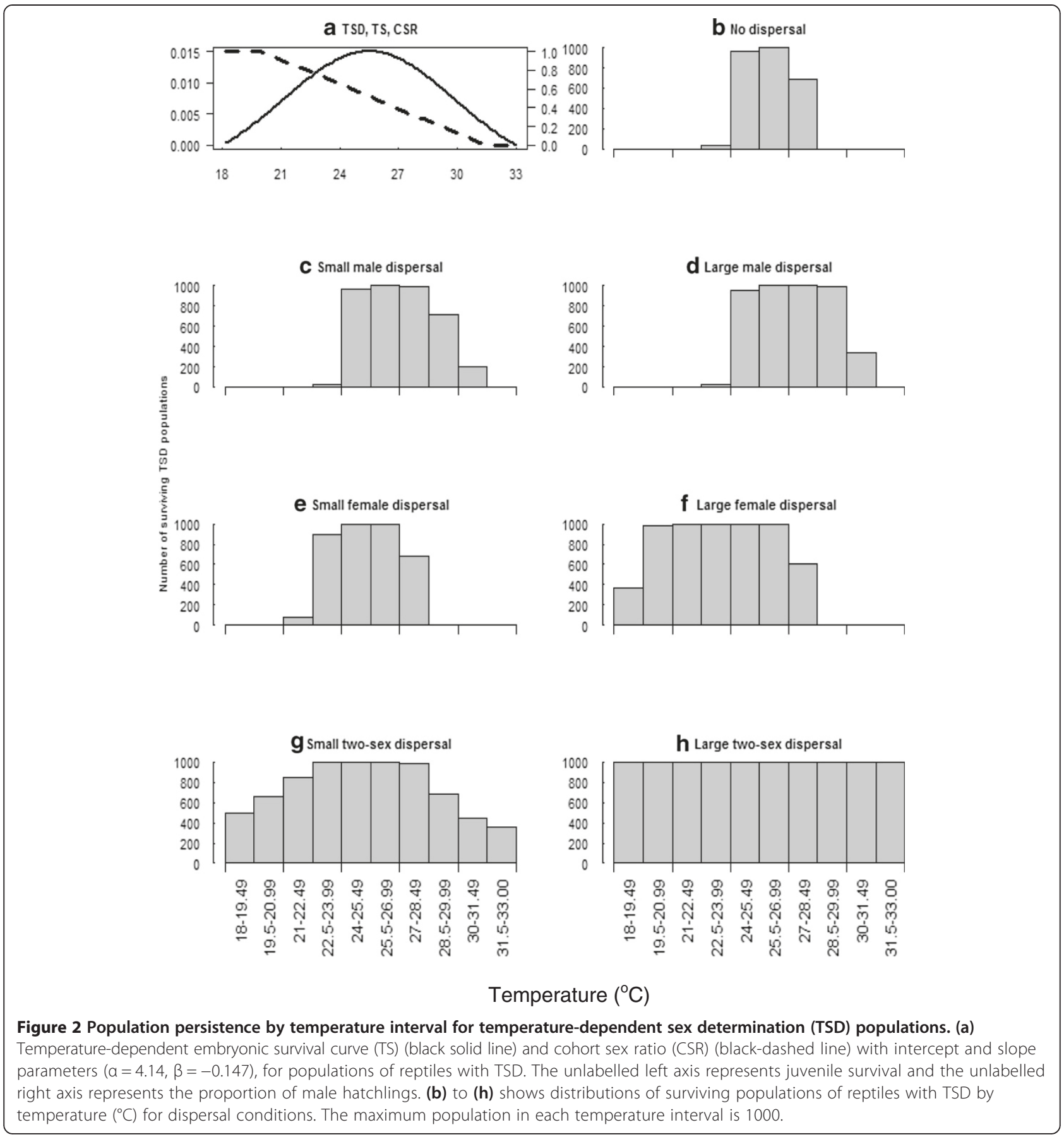

distribution based on the number of offspring produced of each sex and the juvenile survival rate. Juvenile survival rate was density dependent, $a \mathrm{e}^{-c N}$, where $N$ is the total number of adult males and females in the population, $c$ is the density-dependent constant (set to 0.001), and the baseline survival of juveniles $(a)$ depended on temperature according to a normal distribution (the temperature-dependent embryonic survival (TS) curve, [Boyle M, Hone J, Schwanz L, Georges A: Under what conditions do climate-driven sex ratios enhance versus diminish population persistence? Ecology and Evolution. submitted].

The TS curve had a maximum baseline embryonic survival of $a_{\max }=0.015$ (at $25^{\circ} \mathrm{C}$ ) and a minimum baseline survival value of zero. The range of temperatures that produced non-zero baseline juvenile survival probabilities was 18 to $33^{\circ} \mathrm{C}$. Survival rates are based on estimates from published values [44]. The temperature ranges for juvenile survival were similar to those reported for turtles with GSD [45] and TSD [15,46-48]. 


\section{Dispersal function}

Several dispersal scenarios were evaluated owing to insufficient empirical information available to accurately parameterise dispersal in reptile species and variation among species in their dispersal tendencies. We explored three levels of dispersal: none, 'small' and 'large'. However, these terms are relative as there is no readily available information to estimate what small or large dispersal would be in these species. For the 'small' amount of dispersal, juveniles had a higher probability of not dispersing and a lower probability of travelling large distances compared to juveniles with a 'large' amount of dispersal (Figure 1b). 'Small' and 'large' amounts of dispersal had three separate sex-based tendencies, i.e. male only, female only and two-sex dispersal. Under two-sex dispersal, males and females had equal probabilities of dispersing. Due to the stochastic natures of the juvenile sex ratio in each population and the dispersal function (below), the sex ratio of dispersers among cells was therefore also stochastic.

The dispersal function consisted of a probability density function (PDF) based on a fat-tailed (FT) dispersal kernel, which has been shown previously to best approximate dispersal in animals [49]. The FT dispersal kernel describes a scenario where most individuals disperse a short distance or do not disperse at all. In contrast, a small number of individuals disperse a long distance [49], as specified by the function:

$$
\operatorname{Pr}(\text { dispersal distance })=1 /\left(1+A *\left(\mathrm{D}_{\mathrm{ij}}^{Z}\right)\right)
$$

$\operatorname{Pr}($ dispersal distance $)$ is the probability that an individual moves a certain distance, $D_{i j}$, the distance moved between cells or populations. $D_{i j}$ includes a distance of zero, thereby including the probability of not dispersing. Parameter A defines the distribution of dispersal differences, $1 / \mathrm{A}$ is the average dispersal distance, and $\mathrm{Z}$ is a shape parameter for the dispersal curve [50]. Pr(dispersal distance) represents the relative probability that an individual moves a certain distance between cells compared to other possible distances. This was converted to an actual or 'real' probability of dispersing each distance by dividing each relative probability by the sum of the values for all dispersal distances in the matrix (range of distances is 0-198 cells, see below).

Distances were calculated between cells (populations) as a von Neumann neighborhood, which counts the 4 cells immediately to each side of the focal cell as a distance of one, and the diagonal 4 cells as a distance of two [51]. Firstly, dispersal distance for each juvenile in each population was chosen based on the probabilities specified by the dispersal kernel. If a distance of zero was chosen the individual did not disperse and recruited to its natal population. If the distance was greater than zero, the target cell for dispersal was chosen randomly from all cells of the specified distance. Thus, dispersal from the cell in which the individual was born occurred in any direction on the matrix with equal probability. The edge cells of the matrix were defined as the "boundaries' beyond which an individual could move no further. If a dispersal distance was chosen to which no cells corresponded (i.e. off the matrix), a new distance was chosen. Note that maximum possible dispersal distance varied among cells. Only the four corner cells of the matrix had a non-zero probability of dispersing a distance of the maximum 198 cells. Cells along the edge had higher maximum possible dispersal distances, but were constrained to disperse in fewer directions compared to cells in the center, which were more limited in distance but could disperse in more directions. We do not think this variation introduces much bias into the model as the parameter values we chose for the dispersal function specify exceptionally low probabilities of dispersing beyond 20-50 cells. An additional, small probability (0.1) of dispersal-related mortality in juveniles was incorporated into the dispersal algorithm. Dispersal related mortality did not increase with distance moved.

\section{Results}

\section{GSD}

The limits of the range of GSD species (Figure 3) are not strongly influenced by the dispersal scenario, but seem instead to be primarily determined by the shape of the temperature-dependent embryonic survival curve (Figure 3a). Dispersal by males (Figures 3c, d) appears to have the same effect as no dispersal (Figure 3b) on population persistence.

Dispersal does have modest effects on GSD populations when females disperse, but the effects differ between the small (Figure 3e) and large (Figure 3f) amounts of dispersal. The small amount of female dispersal bolsters populations at the edges of the range. This is presumably because of enhanced offspring production by immigrant females at the range margins that counteract the low juvenile survival there (Figure 3e). A large amount of female dispersal results in a reduction in the size of populations near the edge of the range. This is likely because females disperse frequently and far to populations where there are few to no surviving males, so the chances of reproducing are low. Increased dispersal of females out of near-edge populations reduces local reproduction. Thus, female dispersal can either enhance or diminish persistence near the edge of the range depending on how many females leave these populations and whether juvenile survival at the new population is high enough to provide a local supply of males.

Dispersal by both sexes greatly expands the population persistence at most temperatures compared to other 

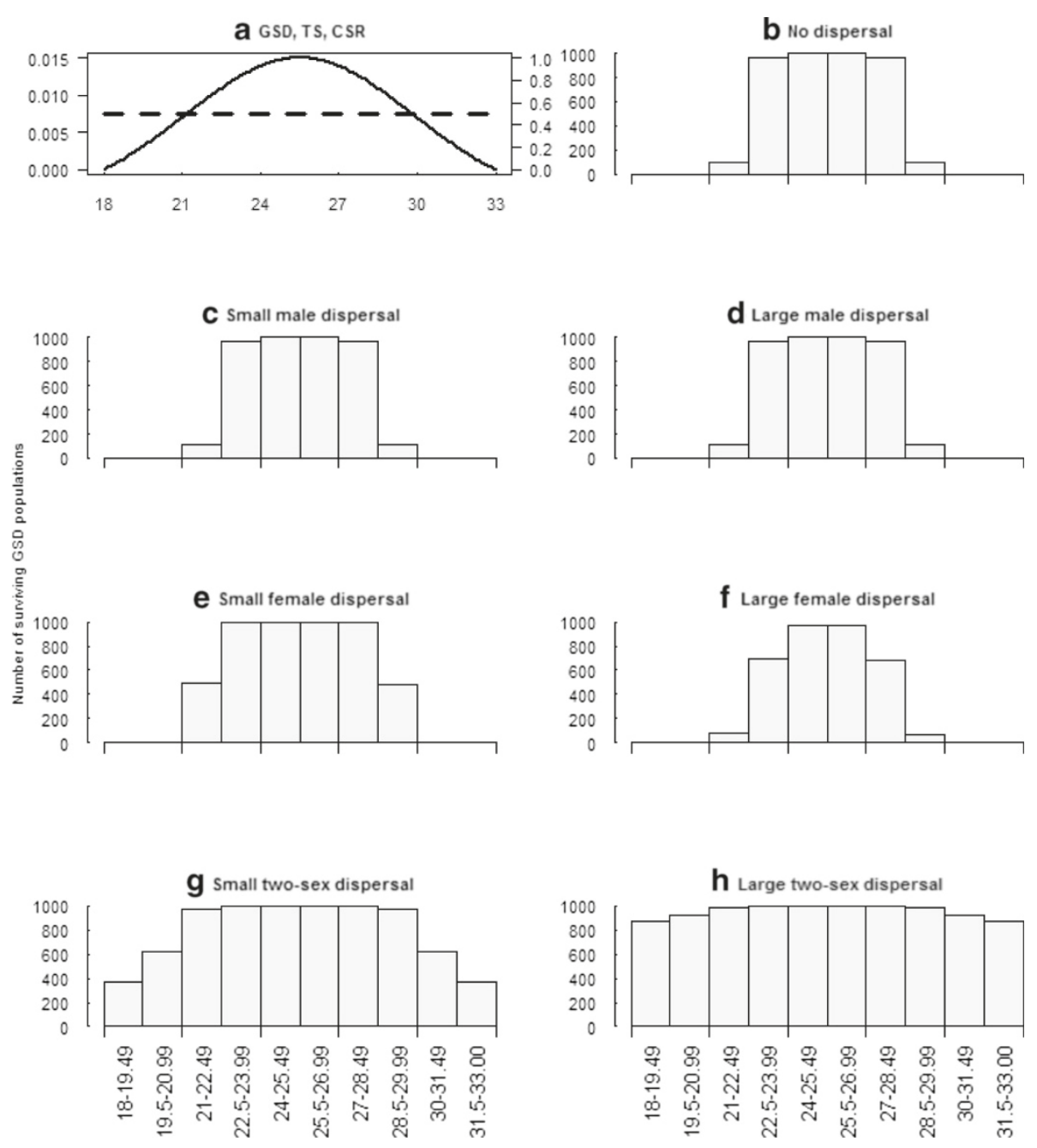

Temperature $\left({ }^{\circ} \mathrm{C}\right)$

Figure 3 Population persistence by temperature interval for genotypic sex determination (GSD) populations. (a) Temperature-dependent embryonic survival curve (TS) (black solid line) and cohort sex ratio (CSR) (black dashed line) with intercept and slope parameters ( $\alpha=0.5, \beta=0.0$ ), for populations of reptiles with GSD. The unlabelled left axis represents juvenile survival and the unlabelled right $y$-axis represents the proportion of male hatchlings. (b) to (h) show the number of and distribution of surviving populations of reptiles with GSD by temperature $\left({ }^{\circ} \mathrm{C}\right)$ for dispersal conditions. The maximum population in each temperature interval is 1000.

dispersal scenarios (Figure 3g). Indeed, for large two-sex dispersal (Figure $3 \mathrm{~h}$ ) the effects of dispersal are so large that most of the initial populations are maintained, except at the highest and lowest temperatures.

TSD

When temperature influences the primary sex ratio, the results share some similarities with GSD, but also have several important differences. For both TSD and GSD species, there are large numbers of surviving populations around the central temperature intervals (from 24 to $28.5^{\circ} \mathrm{C}$, Figures 3 and 2). In TSD species this $4.5^{\circ} \mathrm{C}$ temperature range represents a transition from a slightly male-biased sex ratio (around $60 \%$ male at $24^{\circ} \mathrm{C}$ ) to a very female-biased sex ratio (around $80 \%$ female at $28.5^{\circ} \mathrm{C}$ ). Without dispersal, TSD species have smaller ranges compared to GSD species. The range edge at warm temperatures is reduced modestly owing to decreased female fecundity where males are limiting. The range edge at cool temperatures is strongly reduced owing to low numbers of females, reducing overall offspring production.

Under male dispersal, when males move into warmer areas they encounter increasingly larger numbers of females, and populations are no longer male limited. The importance of male limitation on female fecundity in 
influencing range limits is evident by comparing the results with and without male dispersal (Figure 2b, c, d). In the absence of dispersal (Figure $2 \mathrm{~b}$ ) warm populations are limited by the lack of males. In contrast, small and large amounts of male dispersal result in considerably greater population persistence in warmer areas (Figure 2c, d). Populations in the temperature intervals from 28.5 to $32.5^{\circ} \mathrm{C}$ (Figure 2c, d) benefit most from dispersal by males, as these very female-biased populations are able to persist in warmer areas where they do not in the absence of dispersal. Male dispersal cannot expand the range at the cold edge, where only males are produced, because dispersing males mostly encounter other males.

Female dispersal produces the opposite result to male dispersal, expanding the range in the cool climates. This is because females dispersing to colder areas encounter a higher proportion of males than in populations of reptiles with GSD (Figure 3f). In contrast, if females disperse to warmer areas they encounter only other females, leading to consequent declines in reproduction and population persistence.

Two sex dispersal (Figure 2g, h) increases ranges, similar to GSD species (Figure 3g, h). The shapes of the distributions of TSD and GSD species with two sex dispersal are very similar.

\section{Discussion}

There is increasing evidence that factors such as population dynamics and dispersal strongly interact with abiotic factors such as climate in determining species ranges [3-8]. Species range limits can be strongly influenced by climatic effects on demographic parameters such as juvenile or adult survival, growth and reproduction [1,2]. Dispersal can play a key role in rescuing failing populations or creating "sinks" at range edges. Along range margins if the rate of colonisation via dispersal exceeds local extinctions, the range will expand. By contrast if local extinction events become more frequent than colonisations owing to extreme climates then the species range will shrink [8]. Here, we demonstrate the importance of the sex ratio in limiting species ranges, and explore its interaction with sex-specific dispersal.

Consistent with our previous work and Kallimanis [13], we found that, in the absence of dispersal, species with TSD are restricted in the climates in which they can persist compared to those with GSD owing to biased sex ratios in both warm and cool climates. In contrast to Kallimanis [14], we found that the restriction was greater in cool (male-producing) climates than in warm (female-producing) climates. The difference is owing to assumptions regarding male limitation [Boyle M, Hone J, Schwanz L, Georges A: Under what conditions do climate-driven sex ratios enhance versus diminish population persistence? Ecology and Evolution. submitted] - we assume that female fecundity is only reduced when males are less than $10 \%$ of the adult population.

In addition, we had several novel findings: 1) when both sexes disperse, the existence of biased sex ratios at extreme climates has almost no effect on limiting ranges; 2) male-only dispersal led to ranges covering areas where sex ratios were slightly male-biased to where they were heavily female-biased; 3) female-only dispersal led to ranges covering areas where sex ratios were slightly female-biased to where they were heavily male-biased; 4 ) dispersal scenario was more influential in driving range boundaries in TSD species compared to those with GSD. Our findings provide a clear distinction between populations of reptiles with GSD and TSD in the effect of dispersal at range boundaries, and by inference their responses to climate change. Understanding the sex-specific tendencies of dispersal will be imperative for predicting the possibility of range change for species with TSD.

Female-biased populations have been described as more likely to experience growth than populations with even sex ratios [28]. Furthermore, dispersal by male hatchlings is thought to have an important role in facilitating population persistence in increasingly feminised TSD populations under climatic warming [29]. We have demonstrated that male dispersal increases population persistence in female-biased populations located at warmer areas towards range margins (Figure $2 \mathrm{c}$ and $\mathrm{d}$ ).

We show that population persistence at the colder (male-producing) edge of the range occurs only through female dispersal. Yet female dispersal has only been demonstrated in one GSD reptile, the alpine skink [30]. Skinks are considered to be inefficient at dispersal, and dispersal may occur over very short distances of a few metres [30]. In contrast, male marine turtles are considered to be very effective dispersers and may travel across oceans $[36,37,39,52]$.

Two-sex dispersal has been poorly investigated across species [43]. Dispersal of both sexes in our model resulted in a potential for large ranges for both TSD and GSD species compared to no dispersal (Figure 3g, 3h, $2 \mathrm{~g}, 2 \mathrm{~h})$. This expanded range led to populations persisting even in locations where juvenile survival was almost zero. In these scenarios, populations located at range edges are likely sinks, where the rate of production is below replacement level, and without sufficient immigration may become extinct [10]. Hence, under a climate change scenario, they may have a poor ability to produce their own migrants capable of expanding the range outwards.

Given the strong impact of the sex-bias and distance of dispersal on the results, these will be key behavioural traits to determine empirically when testing our theoretical predictions or making predictions about climate change. In addition, the distance of dispersal in a species 
must be considered with respect the spatial scale of its populations (e.g. distance is measured in number of populations that an individual can pass when dispersing). Our model makes the unique and testable prediction that, when comparing species of reptiles with pattern $1 \mathrm{~A}$ of TSD, those species that have ranges where the sex ratios tend to be female biased will also to have malemediated dispersal, while those that persist where the sex ratios tend to be male biased will have femalemediated dispersal.

While TSD species may persist in the short-term with biased sex ratios at range margins, an important caveat for our results is that populations at range margins (in extreme climates) may evolve in response to frequencydependent selection on sex to produce more even sex ratios [53]. That is, local adaptation in the pivotal temperature (temperature at which a 50:50 sex ratio is produced) or maternal nesting behaviours could occur and reduce geographic variation in cohort sex ratios [54,55]. Existing geographical variation in nesting behaviour (for example, timing, nest depth and shade) may ameliorate the effects of local climate on nest temperatures, thus reduce spatial variation in survival and sex ratio [56]. However, recent work on the co-evolution of the pivotal temperature and dispersal suggests that local adaptation is often limited [11]. Owing to the demographic dominance of females, robust populations that produce a lot of dispersing offspring (i.e. populations with even or female-biased sex ratios) send their locallyadapted genes into other environments where the genes are maladapted and lead to biased sex ratios [11].

A critical assumption of our model is that each sex has an increasing benefit to population growth as the sex ratio becomes biased towards the opposite sex. However, as females become rarer this assumption may not hold anymore. For example, a low density of females has been demonstrated to result in male aggression and population collapse [57].

For our theoretical model to have explanatory power for the distributions of species with TSD, sex ratios must vary spatially. There is some evidence that sex ratios may be constant across the ranges of the painted turtle and the water dragon $[54,55]$. In contrast, sex ratios vary geographically in some sea turtles and crocodiles, although the variation is idiosyncratic and not linked to a continuous spatial component such as latitude $[15,16]$. A recent paper proposes that TSD reptiles do not exhibit balanced sex-ratios at the centre of their geographic distributions, and biased sex-ratios at range margins [16]. Future theoretical work should incorporate evolution of TSD traits as well as spatial variation in sex ratios that is more idiosyncratic across the range.

More broadly, testing our model and understanding the influence of climate of the ranges of species with
TSD requires additional empirical data on the key demographic parameters across the ranges of TSD and GSD species. While data on dispersal are hard to collect, inferences about dispersal can be made from genetic analyses. Genetic analyses of sea turtles suggest that gene-flow is male-mediated and hence male-biased dispersal is the likely pattern [37-39,52]. Crude estimates of dispersal could be made by combining fixation index $\left(\mathrm{F}_{\mathrm{ST}}\right)$ (a measure of population differentiation owing to genetic structure) and demographic parameters. There is also some behavioural data which suggest that malebiased dispersal is the likely pattern in freshwater turtles [40-42], and this could be further investigated using techniques such as radio telemetry.

\section{Conclusions}

Our theoretical model revealed that dispersal was more influential in determining the range limits of species with TSD than GSD. Male dispersal led to expanded species ranges across warm climates, where more females were produced, and female dispersal led to expanded ranges across cool climates, where more males were produced. Two-sex dispersal eliminated the influence of biased sex ratios on ranges.

\section{Competing interests}

The authors declare that they have no competing interests.

\section{Authors' contributions}

$\mathrm{MB}$ contributed to the manuscript writing, modelling, and data analysis (including figures). LS contributed to manuscript writing and editing, modelling, and data analysis. $\mathrm{JH}$ contributed to the manuscript editing and developed the population equations underpinning the model. AG, contributed to the manuscript editing and provided the conceptual framework for the analysis. All authors read and approved the final manuscript.

\section{Acknowledgements}

This study was supported by an Australian Postgraduate Research Award to Maria Boyle, and supplementary funding by the Institute for Applied Ecology at the University of Canberra. Lisa Schwanz was funded by a US National Science Foundation International Research Fellowship and a University of Canberra Postdoctoral Fellowship. We thank the attendees at the Institute journal club for their vigorous discussion of ideas leading up to this paper, and J Lynch for providing comment on an earlier draft. Denis O'Meally established and maintained the high performance computer on which the modelling was done.

\section{Author details}

${ }^{1}$ Institute for Applied Ecology, University of Canberra, Canberra ACT 2601, Australia. ${ }^{2}$ School of Biological, Earth and Environmental Sciences, University of New South Wales, Sydney NSW 2052, Australia.

Received: 6 April 2014 Accepted: 11 June 2014 Published: 10 July 2014

\section{References}

1. Kearney M, Porter W: Mechanistic niche modelling: combining physiological and spatial data to predict species' ranges. Ecol Lett 2009, 12(4):334-350.

2. Sexton JP, McIntyre PJ, Angert AL, Rice KJ: Evolution and ecology of species range limits. Annu Rev Ecol Evol Syst 2009, 40:415-436. 
3. Mustin K, Benton TG, Dytham C, Travis JMJ: The dynamics of climate-induced range shifting; perspectives from simulation modelling. Oikos 2009, 118(1):131-137.

4. Pearson RG, Dawson TP: Predicting the impacts of climate change on the distribution of species: are bioclimate envelope models useful? Glob Ecol Biogeogr 2003, 12(5):361-371.

5. Hampe A: Bioclimate envelope models: what they detect and what they hide. Glob Ecol Biogeogr 2004, 13(5):469-471.

6. Schloss CA, Nunez TA, Lawler JJ: Dispersal will limit ability of mammals to track climate change in the Western Hemisphere. Proc Natl Acad Sci U S A 2012, 109(22):8606-8611.

7. le Roux PC, Virtanen R, Heikkinen RK, Luoto M: Biotic interactions affect the elevational ranges of high-latitude plant species. Ecography 2012, 35(11):1048-1056.

8. Kubisch A, Holt RD, Poethke H-J, Fronhofer EA: Where am I and why? Synthesizing range biology and the eco-evolutionary dynamics of dispersal. Oikos 2014, 123(1):5-22

9. Travis JMJ, Delgado M, Bocedi G, Baguette M, Barton K, Bonte D, Boulangeat I, Hodgson JA, Kubisch A, Penteriani V, Saastamoinen M, Stevens VM, Bullock JM: Dispersal and species' responses to climate change. Oikos 2013, 122(11):1532-1540.

10. Krebs CJ: Ecology. The Experimental Analysis of Distribution and Abundance. 6th edition. New York: Benjamin Cummings; 2009.

11. Kubisch A, Fronhofer EA: Dispersal, evolution and range dynamics - a synthesis. Oikos 2014, 123(1):3-4.

12. Mitchell NJ, Janzen FJ: Temperature-dependent sex determination and contemporary climate change. Sex Dev 2010, 4(1-2):129-140.

13. Kallimanis AS: Temperature dependent sex determination and climate change. Oikos 2010, 119(1):197-200.

14. Janzen FJ, Paukstis GL: Environmental sex determination in reptiles -ecology, evolution, and experimental-design. Q Rev Biol 1991, 66(2):149-179.

15. Hawkes LA, Broderick AC, Godfrey MH, Godley BJ: Investigating the potential impacts of climate change on a marine turtle population. Glob Chang Biol 2007, 13:923-932.

16. Escobedo-Galvan AH, Gonzalez-Salazar C, Lopez-Alcaide S, Arroyo-Pena VB, Martinez-Meyer E: Will all species with temperature-dependent sex determination respond the same way to climate change? A reply to Kallimanis (2010). Oikos 2011, 120(5):795-799.

17. Hays GC, Broderick AC, Glen F, Godley BJ: Climate change and sea turtles: a 150-year reconstruction of incubation temperatures at a major marine turtle rookery. Glob Chang Biol 2003, 9(4):642-646.

18. Hawkes LA, Broderick AC, Godfrey MH, Godley BJ: Climate change and marine turtles. Endanger Species Res 2009, 7(2):137-154.

19. Wapstra E, Uller T, Sinn DL, Olsson M, Mazurek K, Joss J, Shine R: Climate effects on offspring sex ratio in a viviparous lizard. J Anim Ecol 2009, 78(1):84-90.

20. Schwanz LE, Spencer RJ, Bowden RM, Janzen FJ: Climate and predation dominate juvenile and adult recruitment in a turtle with temperature-dependent sex determination. Ecology 2010, 91(10):3016-3026.

21. Telemeco RS, Abbott KC, Janzen FJ: Modeling the effects of climate change induced shifts in reproductive phenology on temperature-dependent traits. Am Nat 2013, 181(5):637-648.

22. Witt MJ, Hawkes LA, Godfrey MH, Godley BJ, Broderick AC: Predicting the impacts of climate change on a globally distributed species: the case of the loggerhead turtle. J Exp Biol 2010, 213(6):901-911.

23. Georges A, Beggs K, Young JE, Doody JS: Modelling development of reptile embryos under fluctuating temperature regimes. Physiol Biochem Zool 2005, 78(1):18-30

24. Rankin DJ, Kokko H: Do males matter? The role of males in population dynamics. Oikos 2007, 116(2):335-348

25. Broderick AC, Godley BJ, Hays GC: Metabolic heating and the prediction of sex ratios for green turtles (Chelonia mydas). Physiol Biochem Zool 2001, 74(2):161-170.

26. Pearse DE, Janzen FJ, Avise JC: Multiple paternity, sperm storage, and reproductive success of female and male painted turtles (Chrysemys picta) in nature. Behav Ecol Sociobiol 2002, 51(2):164-171.

27. Hays GC, Fossette S, Katselidis KA, Schofield G, Gravenor MB: Breeding periodicity for male Sea turtles, operational Sex ratios, and implications in the face of climate change. Conserv Biol 2010, 24(6):1636-1643.

28. Freedberg S, Taylor DR: Sex ratio variance and the maintenance of environmental sex determination. J Evol Biol 2007, 20(1):213-220.
29. Doody JS, Moore JA: Conceptual model for thermal limits on the distribution of reptiles. Herpetol Conserv Biol 2011, 5(2):283-289.

30. Olsson M, Shine R: Female-biased natal and breeding dispersal in an alpine lizard, Niveoscincus microlepidotus. Biol J Linn Soc 2003, 79(2):277-283.

31. Dubey S, Brown GP, Madsen T, Shine R: Male-biased dispersal in a tropical Australian snake (Stegonotus cucullatus, Colubridae). Mol Ecol 2008, 17(15):3506-3514.

32. Doughty $P$, Sinervo $B$, Burghardt GM: Sex-biased dispersal in a polygynous lizard, Uta stansburiana. Anim Behav 1994, 47:227-229.

33. Rassmann K, Tautz D, Trillmich F, Gliddon C: The microevolution of the Galápagos marine iguana Amblyrhynchus cristatus assessed by nuclear and mitochondrial genetic analyses. Mol Ecol 1997, 6(5):437-452.

34. Rivera PC, Gardenal CN, Chiaraviglio M: Sex-biased dispersal and high levels of gene flow among local populations in the argentine boa constrictor, Boa constrictor occidentalis. Austral Ecol 2006, 31(8):948-955.

35. Keogh JS, Webb JK, Shine R: Spatial genetic analysis and long-term mark-recapture data demonstrate male-biased dispersal in a snake. Biol Lett 2007, 3(1):33-35.

36. Laurent L, Casale P, Bradai MN, Godley BJ, Gerosa G, Broderick AC, Schroth W, Schierwater B, Levy AM, Freggi D, Abd El-Mawla NEM, Hadoud DA, Gomati HE, Domingo M, Hadjichristophorou M, Kornaraky L, Dmirayak F, Ch G: Molecular resolution of marine turtle stock composition in fishery bycatch: a case study in the Mediterranean. Mol Ecol 1998, 7(11):1529-1542.

37. Casale P, Laurent L, Gerosa G, Argano R: Molecular evidence of male-biased dispersal in loggerhead turtle juveniles. J Exp Mar Biol Ecol 2002, 267(2):139-145.

38. Roberts MA, Schwartz TS, Karl SA: Global population genetic structure and male-mediated gene flow in the green sea turtle (Chelonia mydas): analysis of microsatellite loci. Genetics 2004, 166(4):1857-1870.

39. Bowen B, Karl S: Population genetics and phylogeography of sea turtles. Mol Ecol 2007, 16(23):4886-4907.

40. Morreale SJ, Gibbons JW, Congdon JD: Significance of activity and movement in the yellow-bellied slider turtle (Pseudemys scripta). Can J Zool 1984, 62(6):1038-1042.

41. Mockford SW, McEachern L, Herman TB, Synder M, Wright JM: Population genetic structure of a disjunct population of Blanding's turtle (Emydoidea blandingii) in Nova Scotia. Can Biol Conserv 2005, 123(3):373-380.

42. Brown GP, Brooks RJ: Sexual and seasonal differences in activity in a northern population of snapping turtles. Chelydra serpentina Herpetologica 1993, 49(3):311-318.

43. Garant D, Forde SE, Hendry AP: The multifarious effects of dispersal and gene flow on contemporary adaptation. Funct Ecol 2007, 21(3):434-443.

44. Heppell SS: Application of life-history theory and population model analysis to turtle conservation. Copeia 1998, 2:367-375.

45. Birchard GF: Effects of Incubation Temperature. In Reptilian Incubation Environment, Evolution and Behaviour. Edited by Deeming DC. Nottingham, UK: Nottingham University Press; 2004:103-123.

46. Yntema CL, Mrosovsky N: Critical periods and pivotal temperatures for sexual-differentiation in loggerhead sea turtles. Can J Zool-Revue Canadienne De Zoologie 1982, 60(5):1012-1016.

47. Schwarzkopf $L$, Brooks RJ: Nest-site selection and offspring Sex-ratio in painted turtles, chrysemys-picta. Copeia 1987, 1:53-61.

48. Steyermark AC, Spotila JR: Body temperature and maternal identity affect snapping turtle (Chelydra serpentina) righting response. Copeia 2001, 4:1050-1057.

49. Chapman DS, Dytham C, Oxford GS: Modelling population redistribution in a leaf beetle: an evaluation of alternative dispersal functions. J Anim Ecol 2007, 76(1):36-44.

50. Moilanen A: SPOMSIM: software for stochastic patch occupancy models of metapopulation dynamics. Ecol Model 2004, 179(4):533-550.

51. Menard A, Marceau DJ: Exploration of spatial scale sensitivity in geographic cellular automata. Environ Plann B-Plann Des 2005, 32(5):693-714.

52. Karl SA, Bowen BW, Avise JC: Global population genetic structure and male-mediated gene flow in the green turtle (Chelonia mydas): RFLP analyses of anonymous nuclear loci. Genetics 1992, 131(1):163-173.

53. Ewert MA, Lang JW, Nelson CE: Geographic variation in the pattern of temperature-dependent sex determination in the American snapping turtle (Chelydra serpentina). J Zool 2005, 265:81-95.

54. Morjan CL: How rapidly can maternal behavior affecting primary sex ratio evolve in a reptile with environmental sex determination? Am Nat 2003, 162(2):205-219. 
55. Doody JS, Guarino E, Georges A, Corey B, Murray G, Ewert M: Nest site choice compensates for climate effects on sex ratios in a lizard with environmental sex determination. Evol Ecol 2006, 270:3-15.

56. Mazaris AD, Kallimanis AS, Pantis JD, Hays GC: Phenological response of sea turtles to environmental variation across a species' northern range. Proc R Soc B-Biol Sci 2013, 280:1751

57. Le Galliard JF, Fitze PS, Ferriere R, Clobert J: Sex ratio bias, male aggression, and population collapse in lizards. Proc Natl Acad Sci U S A 2005, 102(50):18231-18236.

doi:10.1186/1472-6785-14-19

Cite this article as: Boyle et al:: How do climate-linked sex ratios and

dispersal limit range boundaries? BMC Ecology 2014 14:19.

\section{Submit your next manuscript to BioMed Central and take full advantage of:}

- Convenient online submission

- Thorough peer review

- No space constraints or color figure charges

- Immediate publication on acceptance

- Inclusion in PubMed, CAS, Scopus and Google Scholar

- Research which is freely available for redistribution 